\title{
Pain Relief in labour: A randomized controlled trial comparing pentazocine with Tramadol
}

\author{
O. Kuti, AF Faponle, ${ }^{1}$ AB Adeyemi, AT Owolabi \\ Department of Obstetrics, Gynaecology and Perinatology And Anesthesia ' \\ Faculty of Clinical Sciences, Obafemi Awolowo University, Ile-Ife, Nigeria.
}

\begin{abstract}
Aim: To assess and compare the analgesic efficacy and side effects of Pentazocine and Tramadol.

Method: This double blind randomised controlled trial was carried out at the labour ward of Wesley Guild Hospital llesa Nigeria. One hundred normal pregnant women in active labour at term were randomly assigned to receive either intramuscular Pentazocine $30 \mathrm{mg}$ or intramuscular tramadol $100 \mathrm{mg}$, at request for analgesia. Analgesic efficacy was assessed by verbal scales of pain intensity and relief; maternal and neonatal side effects were determined.

Results: At 60 minutes after drug administration $47.7 \%$ and $30.9 \%$ of women, in the pentazocine and tramadol group respectively, experienced moderate to good pain relief. Significantly more women in the pentazocine group $(34.1 \%)$ than in the tramadol group $(14.3 \%)$ rated their pain as mild $(\mathrm{P}<0.05)$ sixty minutes after drug administration.

Mean time to first subsequent request for analgesia was greater in the pentazocine group (181 minutes vs 113 minutes; $\mathrm{P}<0.05)$. There was no significant differences between the drugs in maternal side effects, labour and neonatal outcomes.
\end{abstract}

Conclusion: Pentazocine provides better pain relief than tramadol in labor.

Key words: Labour pain, pentazocine, tramadol

\section{Introduction}

Labour has long been recognized as a very painful event. ${ }^{1}$ Efforts have therefore been made over the years, particularly in the developed world, to relief pain in labour. Unfortunately the same attention has not been given to obstetric analgesia in Africa because of the belief that Africans cope well with labour pains. However a recent study among Nigerian women have shown that most African women find labour extremely painful and will very much welcome measures to relief it. $^{2}$ There is therefore a need for the provision of effective, safe and affordable analgesia in maternity units in Africa. This will make hospital delivery more attractive thereby reducing the incidence of unbooked patients with its attendant high morbidity and mortality.

Epidural analgesia is the most effective analgesia for women in labour. ${ }^{3}$

Unfortunately an epidural service cannot be made routinely available in most obstetric units in developing countries for reasons of cost and personnel. Most labour suites therefore use systemic opioids for analgesia. They are cheap, simple to use and readily available. Since its introduction in 1939, pethidine has become the most commonly used opioids for obstetric analgesia throughout the world despite an unimpressive safety records. ${ }^{4,5}$ Maternal side effects

Correspondence

Dr. O. Kuti FRCOG

Department of Obstetrics, Gynaecology and Perinatology

Faculty of Clinical Sciences

Obafemi Awolowo University, Ile-Ife, Nigeria

E-mail: okuti_victory@yahoo.com. 
include, nausea ,vomiting, sedation and respiratory depression and delayed gastric emptying. ${ }^{3,6,7}$ Pethidine also produces significant respiratory depression of the neonate and behavioral and feeding problems up to six weeks after delivery have been described. ${ }^{8}$

All these adverse effects of pethidine have led to the search for an equally potent but safer systemic analgesics. Other opioids have been tried and the two most commonly available in our country are pentazocine and tramadol.

Pentazocine is a specific kappa-receptor agonist which produces analgesia with little or no respiratory depression. When used for the relief of labour pain many studies have demonstrated equal analgesic effect with better safety profile compared with pethidine. ${ }^{7}$ Tramadol is a synthetic analogue of codeine that binds mu-opiate receptors and inhibits norepinephrine and serotonine uptake. ${ }^{11}$ Studies have shown that tramadol is an effective analgesic without the maternal and neonatal respiratory depression common to other opioids and it does not delay gastric emptying. ${ }^{11-13}$

All the above studies suggest that pentozocine and tramadol may be useful in producing effective pain relief in labour without the adverse effects seen in pethidine. However many of these studies were carried out among Caucasians. In view of possible racial differences in response to analgesia, there is need to evaluate these drugs in an African population where the need for them is more pressing. ${ }^{14}$ The aim of this study, therefore, is to assess and compare the efficacy and safety of pentazocine and tramadol among Nigerian women in labour.

\section{Methods}

This randomized controlled trial was carried out, between June 2005 and May 2006, in the labour ward of Wesley Guild Hospital, Ilesa Nigeria, an arm of the Obafemi Awolowo University teaching Hospitals Complex, Ile-Ife Nigeria. The study was approved by the research and ethical committee of the teaching hospital. Women who were admitted in active spontaneous labour at term with uncomplicated singleton pregnancies were eligible for the study. Active labour was defined as regular uterine contraction at least two in 10 minutes and cervical dilatation of at least $3 \mathrm{~cm}$. Mothers with chronic medical diseases were excluded from the study. Informed consent was obtained from all eligible women who were willing to participate. They were however only entered into the study on request for analgesia.

At first request for analgesia women were randomly allocated to receive either intramuscular injection of Pentazocine 30mg (Laborate Pharmaceuticals, India) or intramuscular Tramadol 100mg.(P.T Interbat, Indonesia) Randomisation was performed using computergenerated random numbers in blocks of four. Randomisation codes were placed in sequentially numbered, opaque, sealed envelope. When each woman requested pain relief, the next numbered envelope was opened and the appropriate drug administered by the randomizing midwife. The labour ward resident Doctor, unaware of the type of injection given, will record the clinical data and assess the analgesic efficacy.

Maternal vital signs (Pulse, Blood pressure, respiratory rate) and labor pain were assessed immediately before, at 30, and 60 minutes after injection of the trial drug. Assessment of labour pain was by a 4 point verbal pain rating scale viz: $\mathrm{o}=$ no pain, $1=$ mild pain, $2=$ moderate pain, $3=$ severe pain. Pain relief was scored as $0=$ none $1=$ mild, $2=$ moderate, $3=$ good . Incidence of maternal vomiting, nausea and sedation were also noted. Maternal sedation was assessed on a three point scale as $0=$ Alert, $1=$ Drowsy, $2=$ Asleep. The time interval to the next request for analgesia was also noted.

Intrapartum monitoring was according to our usual standard labour ward protocol using the partograph. The time and type of delivery were noted. Neonatal condition was assessed by 1 minute and 5 minute Apgar scores, and admission to special care baby unit. Women that delivered within one hour of administration of the trial drug were excluded from further study.

\section{Results}

Of the 100 women recruited for the study 14 (6 in the pentazocine group and 8 in the tramadol group) delivered within one hour of drug administration and were therefore excluded from further analysis. The remaining women, 44 in the pentazocine group and 42 in the tramadol group, had similar characteristics at trial entry as shown in Table 1.

Both drugs produced modest pain relief with $47.7 \%$ of women in the pentazocine group and $30.9 \%$ in the tramadol group reporting moderate to good relief of pain 60 minute after drug administration. Significantly more women in the pentazocine group rated their pain 
Table I. Maternal characteristics at trial entry values are given as $\mathrm{n}(\%)$ or mean [SD]

\begin{tabular}{lccc}
\hline & Pentazocine $\mathrm{n}=44$ & Tramadol $\mathrm{n}=42$ & $\mathrm{P}$ value \\
\hline Age (years) & $29.7[5.1]$ & $30.4[4.9]$ & 0.504. \\
Maternal weight $(\mathrm{kg})$ & $64.5[8.9]$ & $64.5[9.2]$ & 0.996. \\
Gestational Age(weeks) & $39.5[1.6]$ & $39.3[1.4]$ & 0.504. \\
Contraction Frequency of $>=3$ in 10 minutes & $34(77.3)$ & $34 .(80.9)$ & 0.675. \\
Cervical dilatation(cm) & $5.4[1.1]$ & $5.31[1.18]$ & 0.828. \\
Severe $\mathrm{VPI}^{+}$ & $30.0(68.2)$ & $31(73.8)$ & 0.56. \\
\hline
\end{tabular}

+ V PI = Verbal Pain Intensity

as mild and reported better pain relief compared to tramadol group. In the pentazocine group fewer women (59.1\%) needed further analgesia compared to the tramadol group $(64.3 \%)$. Of those who requested further analgesia the mean time to first subsequent request for analgesia was greater in he pentazocine group compared to the tramadol group (181 minutes vs 113 minutes; $\mathrm{P}<0.05)$. Table 2 , shows the effects of pentazocine and tramadol on maternal pain and pain relief.

Table 2. Efficacy of trial drugs as assessed by verbal pain rating and analgesia requirement. Values in $\mathrm{n}(\%)$ or mean [SD]

\begin{tabular}{|c|c|c|c|c|c|}
\hline Pain and relief & Time interval & $\begin{array}{l}\text { Labour pain } \\
\text { severity }\end{array}$ & $\begin{array}{c}\text { Pentazocine } \\
n=44\end{array}$ & $\begin{array}{c}\text { Tramadol } \\
n=42\end{array}$ & $P$ value \\
\hline \multirow{4}{*}{ Pain Rating } & at 30 minutes & Mild & 17(38.6) & $6(14.3)$ & $X^{2}=6.50$ \\
\hline & at 60 minutes & $\begin{array}{l}\text { Moderate/ } \\
\text { Severe }\end{array}$ & $27(61.4)$ & $36(85.7)$ & $\mathrm{P}=0.011$ \\
\hline & & Mild & $15(34.1)$ & $6(14.3)$ & $X^{2}=4.57$ \\
\hline & & $\begin{array}{l}\text { Moderate / } \\
\text { Severe }\end{array}$ & $29(65.9)$ & $36(85.7)$ & $\mathrm{P}=0.03$ \\
\hline \multirow{4}{*}{ Pain relief } & \multirow{2}{*}{ at 30 minutes } & None / Mild & $20(45.5)$ & $32(76.2)$ & $\mathrm{X}^{2}=8.49$ \\
\hline & & $\begin{array}{l}\text { Moderate / } \\
\text { Good }\end{array}$ & $24(54.5)$ & $10(23.8)$ & $\mathrm{P}=0.0036$ \\
\hline & \multirow{2}{*}{ at 60 minutes } & None /Mild & $23(52.3)$ & $29(69.1)$ & $X^{2}=2.53$ \\
\hline & & $\begin{array}{l}\text { Moderate / } \\
\text { Good }\end{array}$ & $21(47.7)$ & 13(30.9) & $\mathrm{P}=0.111$ \\
\hline $\begin{array}{l}\text { Mean time to } \\
\text { first } \\
\text { subsequent } \\
\text { request for } \\
\text { Analgesia } \\
\text { (minutes) }\end{array}$ & & & $181[70.5]$ & $113[41.7]$ & $\begin{array}{l}\mathrm{t}=4.307 \\
\mathrm{P}=0.000\end{array}$ \\
\hline
\end{tabular}


Pain Relief in labour: A randomized controlled trial comparing pentazocine with Tramadol

Table 3. Effect of trial drugs on outcome of labor and delivery. Values given in $n(\%)$ or mean [SD].

\begin{tabular}{lccc}
\hline & Pentazocine $\mathrm{n}=44$ & Tramadol $\mathrm{n}=42$ & $\mathrm{P}$ value \\
\hline $\begin{array}{l}\text { Trial drug administration to delivery interval } \\
\text { (minutes) }\end{array}$ & $256.5[133.2]$ & $213.7[131.1]$ & 0.137 \\
Mode of delivery & & & \\
Spontaneous vaginal delivery & $36(81.8)$ & $37(88.1)$ & \\
Instrumental delivery & $2(4.8)$ & $1(2.4)$ & $\mathrm{X}^{2}=0.66^{*}$ \\
Caesarean section & $6(13.6)$ & $4(9.5)$ & $\mathrm{P}=0.417$ \\
Operative delivery for fetal distress. & $2(4.5)$ & $2(4.8)$ & $\mathrm{P}=1.00$ \\
& & & Fisher exact \\
\hline
\end{tabular}

$* \mathrm{X}^{2}$ values calculated by combining values for instrumental delivery and caesarean section.

Table. 4 Maternal and neonatal side effects. Values in $\mathrm{n}(\%)$

\begin{tabular}{lccc}
\hline & Pentazocine $\mathrm{n}=44$ & Tramadol $\mathrm{n}=42$ & Relative Risk $(\mathbf{9 5 \%} \mathrm{Cl})$. \\
\hline Maternal Drowsiness & $10(22.7)$ & $6(14.3)$ & $0.78(0.50$ to 1.22$)$ \\
Vomiting & $1(2.3)$ & $1(2.4)$ & $0.98(0.24$ to 3.97) \\
Neonatal Apger score at 1 minute $<7$ & $5(11.4)$ & $3(7.1)$ & $1.25(0.70$ to 2.23) \\
Apger score at 5 minutes $<7$ & $1(2.3)$ & $0(0)$ & Not significant \\
Admission to SCBU & $1(2.3)$ & $0(0)$ & Not significant \\
\hline
\end{tabular}

Table 3, shows the effect of the drugs on labour and delivery outcomes. There was no significant difference between the groups on the duration of labour and mode of delivery.

Neither drugs caused significant changes in maternal blood pressure, pulse rate or respiratory rate. Only two women vomited within 2 hours of drug administration ( one in each group). Although, more women in the pentazocine group $(22.7 \%)$ were drowsy compared to the tramadol group (14.3\%), the difference was not statistically significant (RR 0.78;95\% $\mathrm{Cl} 0.50$ to 1.22 ).

Table 4, shows maternal and neonatal effects of the trial drugs. Five babies in the pentazocine group compared to 3 in the tramadol group had apgar scores of less than 7 at one minute. All, except one in the pentazocine group, had a score of less than 7 at 5 minutes. This baby was admitted for neonatal asphyxia at the special care bay unit. He subsequently did well and was discharged on the fourth day.

\section{Discussion}

In this study the level of analgesia provided by either tramadol or pentazocine compares favourably well with that reported for pethidine in the literature. ${ }^{5,15}$ As with pethidine, analgesia with both drugs is generally modest with $30-50 \%$ reporting satisfactory pain relief. Both drugs however showed better safety profile with fewer incidences of vomiting and sedation. Either drug can therefore be safely used in place of pethidine.

Respiratory depression is the most feared adverse effects of opioids. In this study none of the women had respiratory depression. By virtue of their mechanism of actions both drugs have limited effects on the respiratory system. Pentozocine is a kappareceptor partial agonist and tramadol is a synthetic analogue of codeine with low affinity for mu-pioid receptors. Either pathway have been claimed not to depress respiration as do the classic opioids. ${ }^{9,12}$ Both drugs are therefore particularly suitable for use in low -resource settings like Africa.

There was no significant difference between the two drugs with respect to maternal side effects and outcome of labour. However pentazocine had more sedative effect than tramadol. Although both drugs are centrally acting, tramadol combines a weak opioid activity with inhibition of nor-epinephrine and serotonine uptake. ${ }^{10}$ None of the mothers however fell asleep after drug administration. The mild sedative effect of pentazocine may be an advantage for women who are noted to be anxious in labour.

When compared for relief of post-operative pain tramadol was found to be superior to pentazocine. ${ }^{16}$ This study however showed the reverse when used for relief of labour pains. Significantly more women in 
the pentazocine group rated their pains as mild and experienced better pain relief than in the tramadol group. The difference in efficacy under the two settings (postoperative pains and labour pains) is probably due to the difference in the character of the pains. Labour pain is progressive and more likely to be associated with some degree of anxiety. The effect of pentazocine in producing some degree of sedation may explain its better performance in the relief of labour pains. Some studies have shown better analgesic efficacy when sedatives are used as co-drugs with opioids in labor. ${ }^{17}$

\section{Conclusion}

This study showed that both pentazocine and tramadol are safe for the relief of labour pain in our women. Both drugs provide moderate pain relief comparable to that reported for pethidine. Pentazocine however provides better pain relief than tramadol in labor, but it is associated with higher incidence of drowsiness.

There was no significant difference between the two drugs in outcome of labour and neonatal side effects.

\section{References}

1. Melzack R. The myth of painless childbirth. Pain 1984; 19:321-337

2. Kuti O., Faponle AF. Perception of labour pain among the Yoruba ethnic group in Nigeria. J Obstet Gynaecol 2006; 26(4); 322- 334.

3. Jain S, Arya Vk, Gopalan S, Jain V. Analgesic efficacy of intramuscular opioids versus epidural analgesic in labor. Int J Gynecol Obstet 2003; 83 (1): $19-27$

4. Hawkins J.L, Beaty BR. Update on obstetric anesthesia practices in US. Anesthesiology 1999; 91: A1060.

5. Fairlie FM, Marshall L, Walker JJ, Elbourne D. Intramuscular opioids for maternal pain relief in labour: a randomized controlled trial comparing pethidine with diamorphine. Br J Obstet Gynaecol 1999; 106: 1181-1187.

6. Douglas M.J, Levinson G. Systemic medication for labor and delivery in Hugbes SC, Levinson G, Rosen MA, editors. Anesthesia for obstetric, $4^{\text {th }}$ edition. Philadelphia; Lippincot Williams and Wilkins, 2001: 105-121.
7. Elbourne D, Wiseman RA. Types of intramuscular opioids for maternal pain relief in labor. Cochrane database system Rev 2000; (2): CD001237.

8. Nissen E, Widstrom AM, Lilja G et al. Effects of routinely given pethidine during labour on infant developing breastfeeding behaviors. Effects of dose- delivery time interval and various concentrations on pethidine/ norpethidine in cord plasma. Acta paediatr 1997; 86: 201-208.

9. Bourdle TA. Adverse effect of opioids agonist and agonist antagonists in anesthesia. Drug Savety 1998; 19 (3) :173-189.

10. Lee CR, Mc Tavish D, Sorkin EM. Tramadol. A preliminary review of its pharmacodynamic and pharmacokinetic and therapeutic potential in acute and chronic pain states. Drugs 1993; 46(2); 313-340.

11. Bosenberg AT, Ratcliffe $S$. The respiratory effects of Tramadol in children under halothane anesthesia. Anesthesia 1998; 53(10): 960-964.

12. Tarkilla P, Tuominen M, Lindgren L. Comparison of respiratory effect of tramadol and pethidine. Euro J Anesthesiology 1998; 15(1); 64-67.

13. Murphy DB, Sutton A, Prescott LF, Murphy MB. A comparison of the effects of tramadol and morphine on gastric emptying in man. Anaesth 1997; 52(12): 1224-1229.

14. Houghton IT, Aun CST, Gin T, Lau JTF. Interethnic differences in postoperative pethidine requirements. Anaesth Intensive care 1992; 20: $52-55$.

15. Tsui MHY, Ngan kee WD, Ng FF, Lau Tk. Adouble blinded randomised placebo-controlled study of intramuscular pethidine for pain relief in the first stage of labour. BJOG 2004; 111:648-655.

16. Magrini M, Rivolta G, Bolis C, Furiosi D. Analgesic activity of tramadol and pentazocine in postoperative pain. Int J Clinical Pharmacology Research 1998; 18 (2): 87-92.

17. Bricker L, Lavender T. Parenteral opioids for labor pain relief: A systematic review. J Am obstet Gynecol 2002; 186: 594-109. 